\title{
RESONANT FREQUENCY MEASUREMENTS AS AN ALTERNATIVE TO PHASE-SELECTIVE A.C. POLAROGRAPHY IN TENSAMMETRY AND PSEUDOCAPACITANCE DETERMINATIONS
}

\author{
M. BOS* and W. H. M. BRUGGINK
}

Department of Chemical Technology, Twente University of Technology, Enschede (The Netherlands)

(Received 30th December 1982)

\section{SUMMARY}

A new method is proposed for the determination of the double-layer capacitance and pseudocapacitance of electrochemical cells. The method is based on the measurement of the resonant frequency of the circuit consisting of the electrochemical cell connected in series with a standard inductor. The performance of the method is demonstrated with double-layer capacitance measurements at the dropping mercury electrode in $1 \mathrm{M} \mathrm{KCl}$ and butanol-1/1 $\mathrm{M} \mathrm{KCl}$ mixtures and with the determination of heterogeneous charge-transfer rate constants ranging from $10^{-2}$ to $10^{-5} \mathrm{~m} \mathrm{~s}^{-1}$.

Several papers have appeared that describe the use of on-line digital computers in methods for the determination of the double-layer capacitance [1-5]. In this field, three lines of approach can be distinguished: (1) adaptation of phase-selective measurements with lock-in amplifiers or network analyzers to computer control as described by Bongenaar et al. $[3] ;(2)$ the use of the computer to generate a non-sinusoidal cell excitation with a repeating sequence and to produce either Fourier or Hadamard transforms to obtain the cell impedance as first suggested by Creason and Smith [6] and improved by Seelig and de Levie $[1] ;(3)$ the use of computer-generated potential steps as cell excitation and processing of the resulting cell current/ time profile as proposed by Bos [4] and Britz [5].

A comparison of the three categories shows that the first requires expensive extra hardware such as programmable function generators and network analyzers or lock-in amplifiers. The second category relies on a stringent time relationship between the excitation signal and the sampling of the cell response and requires special computer hardware. Both the first and the second category require analog circuitry for the potentiostat, $i R$ compensation and $i$-to- $E$ conversion functions. The accuracy of the results will depend on the quality of this circuitry with regard to flat frequency response, linearity, stability and the magnitude of the phase shift introduced by the $i R$ compensation circuitry. In the presence of electroactive compounds, the measurements in the first and second categories can provide information on the double-layer capacitance as well as on the kinetics of the electrode reactions. 
The experimental set-up for the third category is rather simple; it consists of the electrochemical cell and the computer. Accuracy in the current measurements is the only important requirement. A drawback of the method presented earlier [4] is that in the presence of electroactive compounds broad pseudocapacitance peaks occur that prohibit tensammetric determinations in a certain potential range around their respective standard potentials.

The method proposed now also utilizes a simple experimental set-up. The electrochemical cell is connected in series with an inductor to form a resonant circuit, the resonant frequency of which is determined by measuring the frequency of the dampened sine wave that results if a single short pulse is applied to the system. The amplitude information in the cell response signal is not utilized, so demands with regard to the instrumentation are minimal. The accuracy of the results will be determined by the absolute value and the stability of the fixed rate with which the cell response is sampled by the computer. A simple crystal-controlled timer, such as can be found on most microprocessor boards, amply provides the required accuracy in timing for this purpose. The information produced by the new method is equivalent to that obtained from phase-selective a.c. polarography in which the cell current is measured exactly $90^{\circ}$ out of phase with the applied a.c. voltage and can be used in the same way, i.e., in the study of the electrical double layer at the dropping mercury electrode and solid electrodes, adsorption phenomena on electrodes and in the study of the kinetics of electrode reactions.

\section{THEORY}

The equivalent circuit for the combination of the electrochemical cell and an inductor is given in Fig. 1. Its resonant frequency is given by

$f_{\text {reson. }}=1 /\left[2 \pi\left(L C_{\mathrm{eq}}\right)^{1 / 2}\right]$

With this equation the equivalent capacitance of the circuit, $C_{\text {eq }}$, can easily be determined from the resonant frequency if a known inductor $L$ is used. In the absence of electroactive components, $C_{\text {eq }}$ equals the capacitance of the electrical double layer, $C_{\text {edl }}$; thus for adsorption studies in nonelectroactive electrolytes the method directly produces the quantity of interest. In the presence of an electroactive component, the electrochemical cell can be represented by the circuit given in Fig. 2, the lower branch of which constitutes the faradaic impedance. The latter consists of a frequency-independent activation resistance, $\Theta$, and a frequency-dependent Warburg impedance, $W$. According to Sluyters-Rehbach [7], the following equations can be derived for the terms in the faradaic impedance

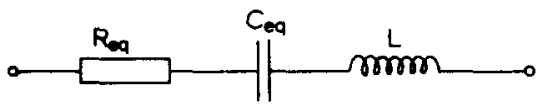

Fig. 1. Equivalent circuit of electrochemical cell/inductor combination. 

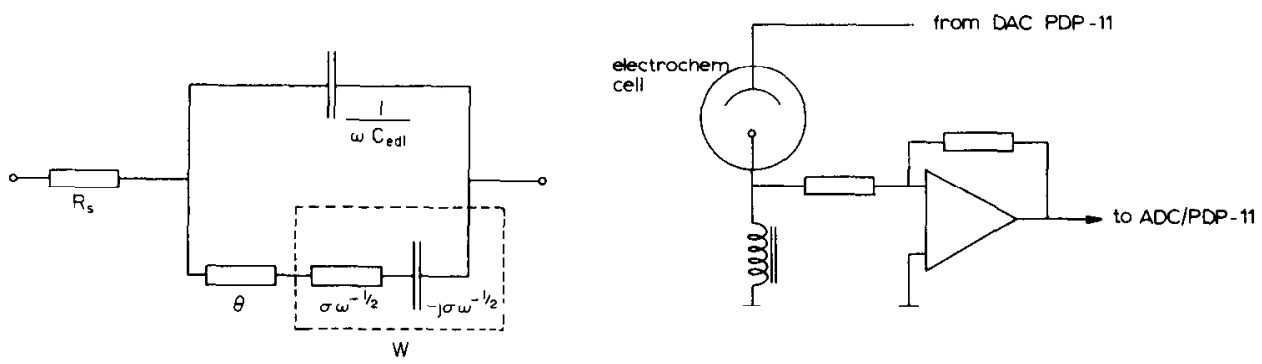

Fig. 2. Equivalent circuit of electrochemical cell with electroactive component.

Fig. 3. Electrochemical cell circuitry.

$$
\begin{aligned}
& \Theta=R T /\left[n^{2} F^{2} k_{\mathrm{sh}}\left(C_{\mathrm{ox}}^{0}\right)^{\alpha}\left(C_{\mathrm{Red}}^{0}\right)^{1-\alpha}\right] \\
& \sigma=\left(R T / n^{2} F^{2} 2^{1 / 2}\right)\left\{\left[1 / C_{\mathrm{ox}}^{0}\left(D_{\mathrm{ox}}\right)^{1 / 2}\right]+\left[1 / C_{\mathrm{Red}}^{0}\left(D_{\mathrm{Red}}\right)^{1 / 2}\right]\right\} \\
& C_{\mathrm{ox}}^{0}=\left(C_{\mathrm{ox}}^{*}+d^{1 / 2} C_{\mathrm{Red}}^{*}\right) /\left(1+d^{1 / 2} e^{-\phi}\right) \quad C_{\mathrm{Red}}^{0}=\left(C_{\mathrm{ox}}^{*}+d^{1 / 2} C_{\mathrm{Red}}^{*}\right) /\left(e^{\phi}+d^{1 / 2}\right) \\
& \phi=n F\left(E-E_{0}\right) / R T \quad d=D_{\mathrm{Red}} / D_{\mathrm{ox}}
\end{aligned}
$$

(Symbols are defined in Table 1.)

For potentials far from the standard potential of the electroactive component, the faradaic impedance is infinite, so that in this case the system again measures directly the capacitance of the electrical double layer. In the region of the standard potential of electroactive components, the equivalent capacitance $C_{\mathrm{eq}}$ measured by the system comprises not only the double-layer capacitance $C_{\text {ed1 }}$ but also depends on the value of the terms of the faradaic impedance. From a vector diagram of the circuit presented in Fig. 2, it can be found that

$$
C_{\text {eq }}=\frac{\omega^{2} C_{\text {ed } 1}^{2} \Theta^{2}+2 \omega^{3 / 2} C_{\mathrm{ed} 1}^{2} \sigma \Theta+2 \omega C_{\mathrm{edl}}^{2} \sigma^{2}+2 \omega^{1 / 2} C_{\mathrm{ed} 1} \sigma+1}{\omega^{2} C_{\mathrm{ed} 1} \Theta^{2}+2 \omega^{3 / 2} C_{\mathrm{edl}} \sigma \Theta+2 \omega C_{\mathrm{edl}} \sigma^{2}+\omega^{1 / 2} \sigma}
$$

This equation can be used in several ways. The actual choice will depend on the goal of the measurements. Thus, the double-layer capacitance at a given potential in the presence of an electroactive compound can be determined from a single measurement, if $\Theta$ and $\sigma$ are known. These latter values can be calculated from Eqns. (2) and (3) and the appropriate relationship for $C_{0 x}^{0}$ and $C_{\mathrm{Red}}^{\mathrm{o}}$ as a function of electrode potential, as expressed by Eqns. (4) and (5). In this case the values of $E_{0}, \alpha, k_{\mathrm{sh}}, D_{\mathrm{ox}}, D_{\mathrm{Red}}, C_{\mathrm{ox}}^{*}$ and $C_{\mathrm{Red}}^{*}$ must be available. If these values cannot be readily obtained, Eqn. (6) can be used in a three-parameter $\left(C_{\text {edl }}, \sigma\right.$ and $\left.\Theta\right)$ curve-fitting procedure using a number of $C_{\text {eq }}, \omega$ data pairs measured at different electrode areas, or at different concentrations using normalized parameters $\Theta c$ and $\sigma c$. This enables $C_{\text {ed1 }}$ to be determined in the potential range of the a.c. wave of electroactive components $[7,8]$. Should the method be used for the study of rate constants the $\Theta$ value found in the three-parameter curve-fitting procedure can be used together with Eqns. (2), (4) and (5) to give $k_{\mathrm{sh}}$. 
TABLE 1

List of sy mbols

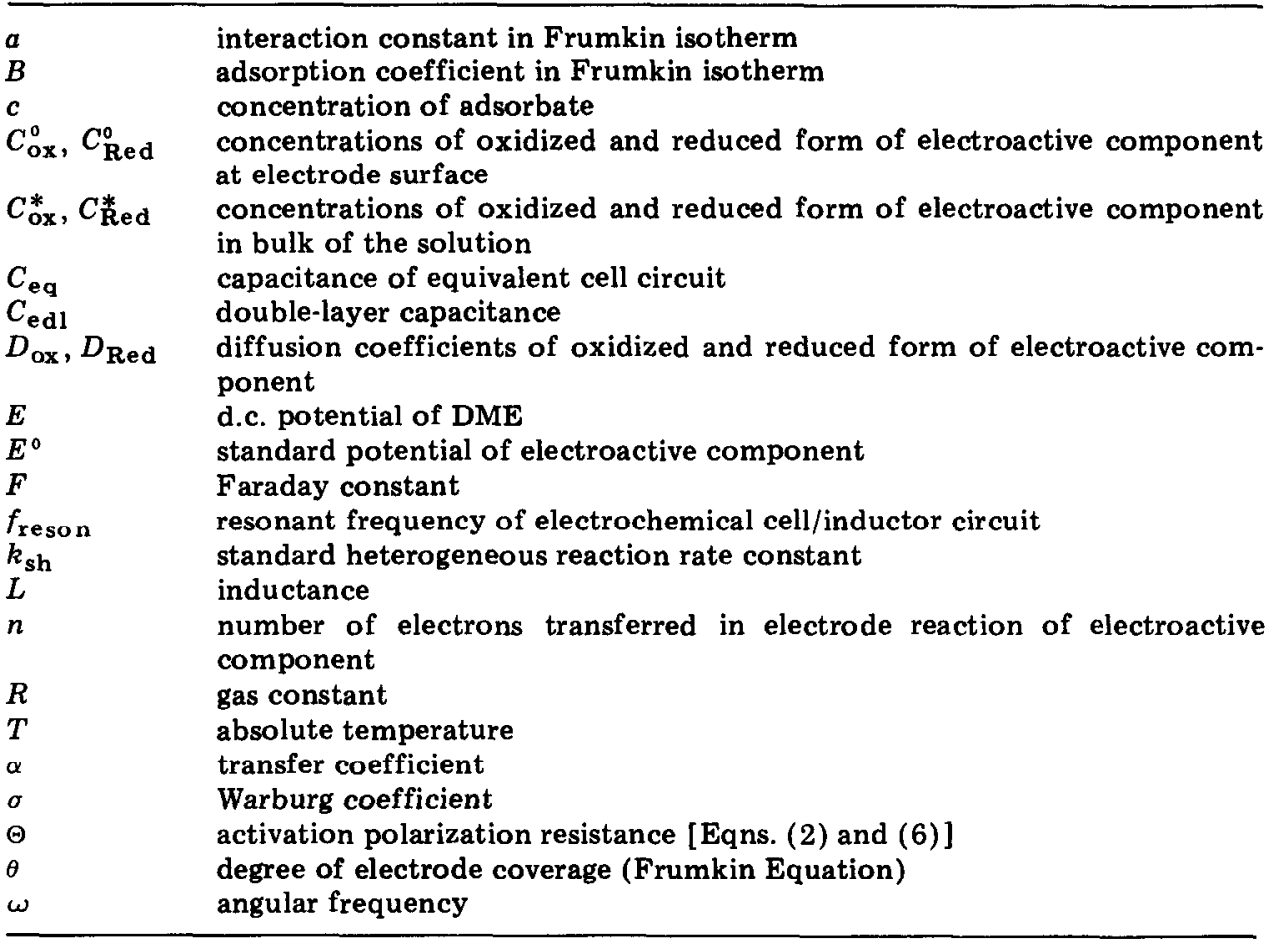

\section{EXPERIMENTAL}

\section{Chemicals and equipment}

The following compounds were used as received: potassium chloride, sodium sulphate, iron(III) ammoniumsulphate, oxalic acid, potassium oxalate, potassium sulphate, butanol-1 (all from Merck, quality "Zur Analyse"), cadmium chloride (AnalaR, analytical reagent), cadmium sulphate (Merck, Suprapur), nitrogen (Hoekloos, very pure) and mercury (Drijfhout, polarographic grade). All solutions were made with deionized water filtered through Millipore Q2 filters.

All measurements were done in solutions that had been stripped of oxygen by bubbling with nitrogen for $20 \mathrm{~min}$.

The electrochemical cell consisted of a cylindrical vessel $(57.1 \mathrm{~mm}$ tall, $34.3 \mathrm{~mm}$ diameter). A mercury pool at the bottom of this vessel was used as the counter electrode. The characteristics of the dropping mercury electrode (DME) were $h=40 \mathrm{~cm}, t=3.6 \mathrm{~s}, m=2.39 \mathrm{mg} \mathrm{s}^{-1}$ ( $1 \mathrm{M} \mathrm{KCl}$, open circuit). A Radiometer drop-life timer, type DLT 1, was used for computer-controlled drop knock off. A schematic diagram of the connections of the electro- 
chemical cell to the PDP-11/10 (Digital Equipment Corp.) on-line computer is presented in Fig. 3. The operational amplifier was from Keithley, model 301. The digital-to-analog converter (DAC) and analog-to-digital converter (ADC) were standard Digital Equipment Corp. interfaces contained in the laboratory peripheral system with 12-bit accuracy. The ADC was operated in the direct memory access (DMA) mode under control of the programmable real-time clock (LPSKW) of the computer. The inductor in series with the cell was a $88 \mathrm{mH}$ toroid (Miller).

\section{Computer program}

A flow chart of the computer program that controls the experiments is given in Fig. 4. The program starts with an initial dialogue in which the operator can set the required experimental parameters for the d.c. scan, the drop time and the number of measurements at the same d.c. potential to be taken and averaged to improve the signal-to-noise ratio. Then the program applies the initial voltage of the wanted d.c. scan range to the cell and knocks off the first drop. If the mercury drop of the working electrode has reached its predetermined lifetime, the program continues with starting the ADC burst of 4096 data points. Directly after the start of this burst, a $5-\mu \mathrm{s} 600-\mathrm{mV}$ pulse is applied to the cell voltage. The corresponding amplitude of the a.c. voltage generated across the double layer depends on its impedance but is generally much less than $20 \mathrm{mV}$. The measurement cycle can be repeated a number of times at the same d.c. scan potential at successive mercury drops to improve the signal-to-noise ratio. If the wanted number of bursts has been acquired, the program calculates the Fourier transform of the 4096-point data buffer. This is followed by calculation of the power spectrum of the Fourier transform. The resonant frequency of the cell circuit is then calculated from the position of the maximum in this power spectrum. Finally, the equivalent capacitance of the circuit is calculated by using Eqn. (1), and printed on teletype together with the value of the resonant frequency. The capacitance value is also displayed on a stripchart recorder connected to a DAC. The whole process is repeated until the end of the scan range is reached.

\section{RESULTS AND CONCLUSIONS}

The accuracy of the system was checked against a standard capacitance decade bank. From the results given in Table 2, it can be seen that the mean error is $\pm 2.3 \%$, whereas the range that is covered with the fixed $88-\mathrm{mH}$ inductor in the circuit extends from $0.05 \mu \mathrm{F}$ to $2 \mu \mathrm{F}$. The performance of the system for samples not containing any electroactive compounds was tested by measurement of the differential capacity versus potential curve for $1 \mathrm{M}$ potassium chloride (Table 3 ) and in the determination of the Frumkin adsorption isotherm constants for butanol-1 in this electrolyte (Fig. 5). As can be seen, the measured capacitance values for $1 \mathrm{M}$ potassium chloride 


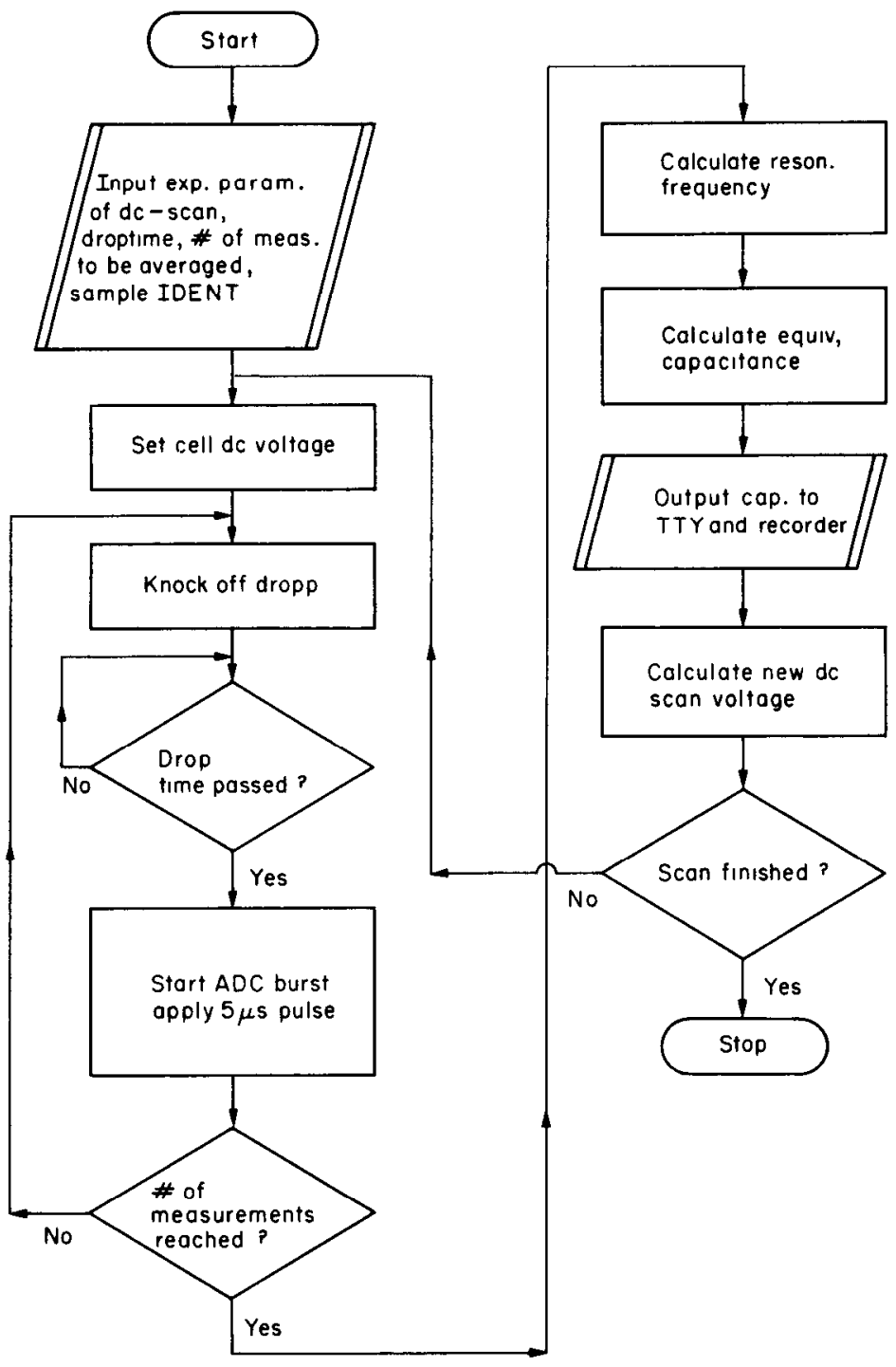

Fig. 4. Flow chart of computer program for resonant frequency measurements.

agree to within $\pm 5 \%$ with the literature data [9]. From the adsorption isotherm in Fig. 5 the constants $a$ and $B$ for butanol- 1 in $1 \mathrm{M} \mathrm{KCl}$ were calculated from the Frumkin equation $B c=[\theta /(1-\theta)] \exp (-2 a \theta)$, to be 1.29 and 10.7, respectively. Boravaya and Damaskin [10] reported values of 1.28 and 8.6.

The accuracy of the system at constant d.c. voltage across the cell was tested by using various drop times for a $0.5 \mathrm{M}$ sodium sulphate solution. The results are given in Table 4. 
TABLE 2

Performance of system with standard capacitances

\begin{tabular}{lllllr}
\hline $\begin{array}{l}\text { Capacity } \\
\text { used } \\
(\mu \mathrm{F})\end{array}$ & $\begin{array}{l}\text { Capacity } \\
\text { found } \\
(\mu \mathrm{F})\end{array}$ & $\begin{array}{l}\text { Error } \\
(\%)\end{array}$ & $\begin{array}{l}\text { Capacity } \\
\text { used } \\
(\mu \mathrm{F})\end{array}$ & $\begin{array}{l}\text { Capacity } \\
\text { found } \\
(\mu \mathrm{F})\end{array}$ & $\begin{array}{l}\text { Error } \\
(\%)\end{array}$ \\
\hline 0.050 & 0.048 & -4.0 & 0.600 & 0.600 & 0.0 \\
0.100 & 0.098 & -2.0 & 0.700 & 0.678 & -3.1 \\
0.200 & 0.199 & -0.5 & 0.800 & 0.771 & -3.6 \\
0.300 & 0.301 & +0.3 & 0.900 & 0.885 & -1.6 \\
0.400 & 0.393 & -1.8 & 1.000 & 0.952 & -4.8 \\
0.500 & 0.480 & -4.0 & 2.000 & 1.923 & -3.9 \\
\hline
\end{tabular}

The use of the system to acquire data on electrode kinetics was tested for a number of electrochemical systems with heterogeneous charge-transfer rate constants ranging from $4 \times 10^{-2}$ to $4 \times 10^{-5} \mathrm{~m} \mathrm{~s}^{-1}$. The experimental data are given in Table 5. The measurements were made at the d.c. potential of the pseudocapacitance peaks. For the fastest reaction (i.e., cadmium in $1 \mathrm{M} \mathrm{KCl}$ ) the three-parameter curve-fitting procedure with the use of Eqn. (6) did not work because of the small magnitude of the $\Theta$ terms in comparison with the error in the capacitance measurements. If the $\Theta$ terms are neglected and the Warburg constant $\sigma$ is calculated with the value $0.265 \mathrm{~F} \mathrm{~m}^{-2}$ for the doublelayer capacitance for the different concentrations of cadmium, it shows a good inverse proportionality with the concentration $\left(\sigma \times\right.$ conc. $=8.4 \times 10^{-3}$ $\left.\pm 0.5 \times 10^{-3} \Omega \mathrm{m}^{-1} \mathrm{~s}^{-1 / 2} \mathrm{~mol}\right)$.

The system iron(III) oxalate in $1.0 \mathrm{M}$ potassium oxalate- $0.05 \mathrm{M}$ oxalic acid has a reported [11] $k_{\mathrm{sh}}$ value of $0.0148 \mathrm{~m} \mathrm{~s}^{-1}$. Three-parameter curvefitting of the data in Table 5 to Eqn. (6) gives the values $\Theta c=3.8 \times 10^{-5}$ $\left(\Omega \mathrm{mol} \mathrm{m}{ }^{-1}\right), \sigma c=3.5 \times 10^{-2}$ and $C_{\mathrm{ed} 1}=0.145 \mathrm{~F} \mathrm{~m}^{-2}$. Use of Eqns. (2), (4) and (5) with $D_{\text {ox }}=D_{\text {Red }}=4.94 \times 10^{-10} \mathrm{~m}^{2} \mathrm{~s}^{-1}$ produces a $k_{\mathrm{sh}}$ value of 0.014 $\mathrm{m} \mathrm{s}^{-1}$, which is in good agreement with the literature value mentioned above.

\section{TABLE 3}

Double-layer capacitance data at the DME for $1 \mathrm{M}$ potassium chloride

\begin{tabular}{llllll}
\hline $\begin{array}{l}\text { DME potential } \\
\text { (V vs. NCE) }\end{array}$ & $\begin{array}{l}\text { Capacitance } \\
\text { found } \\
\left(\mathrm{F} \mathrm{m}^{-2}\right)\end{array}$ & $\begin{array}{l}\text { Lit. } \\
\text { value }[9] \\
\left(\mathrm{F} \mathrm{m}^{-2}\right)\end{array}$ & $\begin{array}{l}\text { DME potential } \\
(\mathrm{V} \text { v8. NCE) }\end{array}$ & $\begin{array}{l}\text { Capacitance } \\
\text { found } \\
\left(\mathrm{F} \mathrm{m}^{-2}\right)\end{array}$ & $\begin{array}{l}\text { Lit. } \\
\text { value [9] } \\
\left(\mathrm{F} \mathrm{m}^{-2}\right)\end{array}$ \\
\hline-0.200 & 0.400 & 0.420 & -0.800 & 0.178 & 0.192 \\
-0.300 & 0.373 & 0.392 & -0.900 & 0.170 & 0.172 \\
-0.400 & 0.430 & 0.420 & -1.000 & 0.155 & 0.164 \\
-0.500 & 0.400 & 0.408 & -1.100 & 0.155 & 0.160 \\
-0.600 & 0.307 & 0.316 & -1.200 & 0.162 & 0.164 \\
\hline-0.700 & 0.229 & 0.240 & & & \\
\hline
\end{tabular}




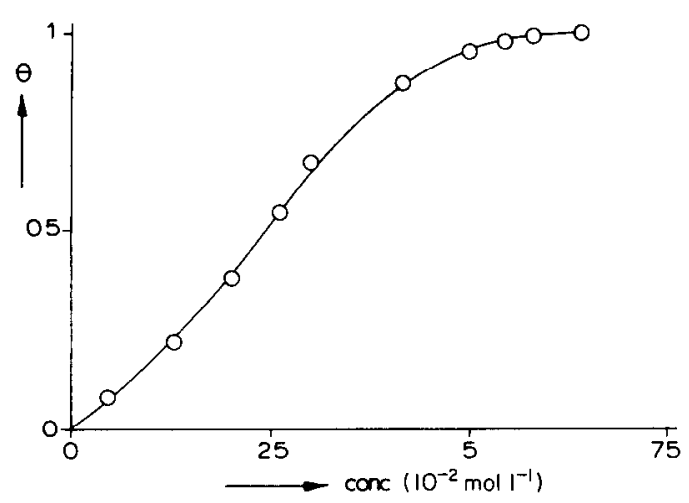

Fig. 5. Adsorption isotherm for butanol-1 in $1 \mathrm{M} \mathrm{KCl}$ at $-0.6 \mathrm{~V}$ vs. SCE.

The $k_{\text {sh }}$ value for cadmium-ion reduction in $0.5 \mathrm{M} \mathrm{K}_{2} \mathrm{SO}_{4}$ given by Tanaka and Tamamushi [12] is $8 \times 10^{-4} \mathrm{~m} \mathrm{~s}^{-1}$. The three-parameter curve-fitting procedure for this system gave $\Theta c=3.2 \times 10^{-4}, \sigma c=9.5 \times 10^{-3}$ and $C_{\mathrm{edl}}=$ $0.22 \mathrm{~F} \mathrm{~m}^{-2}$. From the $\Theta$ value and $D_{\mathrm{ox}}=6.6 \times 10^{-10} \mathrm{~m}^{2} \mathrm{~s}^{-1}$ and $D_{\text {Red }}=1.53 \times$ $10^{-9} \mathrm{~m}^{2} \mathrm{~s}^{-1}$, the $k_{\mathrm{sh}}$ value is found to be $5.2 \times 10^{-4} \mathrm{~m} \mathrm{~s}^{-1}$. Although the agreement with the earlier value is somewhat disappointing, the result for the double-layer capacitance is in good agreement with the value measured in the absence of the electroactive component $\left(0.22 \mathrm{vs} 0.21 \mathrm{~F} \mathrm{~m}^{-2}\right)$. For the slowest reaction tested (i.e., zinc ions in $1 \mathrm{M} \mathrm{KCl}$ with $k_{\mathrm{sh}}=3 \times 10^{-5}-4 \times 10^{-5} \mathrm{~m} \mathrm{~s}^{-1}$ ) the $\sigma$ terms in Eqn. (6) are small compared to the $\Theta$ terms; thus in the threeparameter curve-fitting the results for $\sigma$ will be unreliable. However, $\Theta$ and the double-layer capacitance can be found with satisfactory accuracy. The results found for the data given in Table 5 are: $C_{\mathrm{edl}}=0.166 \mathrm{~F} \mathrm{~m}^{-2}$ and $\Theta c$ $=5.8 \times 10^{-3}$. This double-layer capacitance is in good agreement with the value measured in the absence of electroactive material $\left(0.162 \mathrm{~F} \mathrm{~m}^{-2}\right)$. The product $\Theta c=5.8 \times 10^{-3}$ together with $D_{\text {ox }}=7.9 \times 10^{-10}$ and $D_{\text {Red }}=1.6 \times$ $10^{-9}$ leads to $k_{\mathrm{sh}}=2.8 \times 10^{-5} \mathrm{~m} \mathrm{~s}^{-1}$ which is also in good agreement with its earlier value [9].

\section{TABLE 4}

Double-layer capacitance for the DME at $-0.86 \mathrm{~V}$ vs. saturated mercury(I) sulphate at various drop times for $0.5 \mathrm{M} \mathrm{Na}_{2} \mathrm{SO}_{4}$

\begin{tabular}{llll}
\hline $\begin{array}{l}\text { Drop time } \\
(\mathrm{s})\end{array}$ & $\begin{array}{l}\text { Capacitance } \\
(\mu \mathrm{F})\end{array}$ & $\begin{array}{l}\text { Drop area } \\
\left(\mathrm{mm}^{2}\right)\end{array}$ & $\begin{array}{l}\text { Specific capacitance } \\
\left(\mathrm{F} \mathrm{m}^{-2}\right)\end{array}$ \\
\hline 0.96 & 0.314 & 1.48 & 0.213 \\
1.44 & 0.393 & 1.94 & 0.203 \\
1.92 & 0.507 & 2.34 & 0.216 \\
2.40 & 0.566 & 2.72 & 0.208
\end{tabular}

Mean $0.210 \pm 0.006 \mathrm{~F} \mathrm{~m}^{-2}$ 
TABLE 5

Pseudocapacitance measurements for systems with different $k_{\text {sh }}$ values (peak values)

\begin{tabular}{|c|c|c|c|c|}
\hline $\begin{array}{l}\text { Active } \\
\text { component }\end{array}$ & $\begin{array}{l}\text { Conc. } \\
\left(\mathrm{mol} \mathrm{m}^{-9}\right)\end{array}$ & $\begin{array}{l}\text { Drop time } \\
\text { (s) }\end{array}$ & $\begin{array}{l}\text { Specific } \\
\text { capacitance } \\
\left(\mathrm{F} \mathrm{m}^{-2}\right)\end{array}$ & $\begin{array}{l}\text { Frequency } \\
(\mathrm{Hz})\end{array}$ \\
\hline $\mathrm{Cd}^{2+\mathrm{a}}$ & $\begin{array}{l}0.075 \\
0.075 \\
0.075 \\
0.075 \\
0.1875 \\
0.1875 \\
0.1875 \\
0.1875 \\
0.375 \\
0.375\end{array}$ & $\begin{array}{l}0.96 \\
1.44 \\
1.92 \\
2.40 \\
0.96 \\
1.44 \\
1.92 \\
2.88 \\
0.96 \\
1.44\end{array}$ & $\begin{array}{l}0.343 \\
0.350 \\
0.352 \\
0.378 \\
0.645 \\
0.530 \\
0.612 \\
0.626 \\
0.971 \\
0.994\end{array}$ & $\begin{array}{l}726 \\
625 \\
564 \\
504 \\
524 \\
504 \\
423 \\
363 \\
423 \\
363\end{array}$ \\
\hline $\begin{array}{l}\text { Iron(III) } \\
\text { oxalate }^{\text {b }}\end{array}$ & $\begin{array}{l}0.98 \\
0.98 \\
0.98 \\
0.98\end{array}$ & $\begin{array}{l}0.48 \\
0.96 \\
1.44 \\
1.92\end{array}$ & $\begin{array}{l}0.423 \\
0.559 \\
0.574 \\
0.514\end{array}$ & $\begin{array}{l}826 \\
564 \\
484 \\
464\end{array}$ \\
\hline $\mathrm{Cd}^{2+c}$ & $\begin{array}{l}0.9 \\
0.8 \\
0.7 \\
0.6 \\
0.5 \\
0.4 \\
0.3 \\
0.2\end{array}$ & $\begin{array}{l}0.84 \\
0.84 \\
0.84 \\
0.84 \\
0.84 \\
0.84 \\
0.84 \\
0.84\end{array}$ & $\begin{array}{l}0.908 \\
0.952 \\
0.606 \\
0.683 \\
0.545 \\
0.291 \\
0.323 \\
0.254\end{array}$ & $\begin{array}{l}547 \\
516 \\
632 \\
581 \\
669 \\
847 \\
806 \\
907\end{array}$ \\
\hline $\mathrm{Zn}^{2+\mathrm{a}}$ & $\begin{array}{l}7.39 \\
4.95 \\
4.95 \\
4.95 \\
4.95 \\
4.95\end{array}$ & $\begin{array}{l}0.96 \\
0.96 \\
1.44 \\
1.92 \\
2.40 \\
2.88\end{array}$ & $\begin{array}{l}0.464 \\
0.355 \\
0.354 \\
0.292 \\
0.494 \\
0.877\end{array}$ & $\begin{array}{l}826 \\
947 \\
826 \\
826 \\
586 \\
403\end{array}$ \\
\hline
\end{tabular}

${ }^{a}$ In $1 \mathrm{M} \mathrm{KCl} .{ }^{b}$ In $1 \mathrm{M} \mathrm{K}_{2} \mathrm{C}_{2} \mathrm{O}_{4} / 0.05 \mathrm{M} \mathrm{H}_{2} \mathrm{C}_{2} \mathrm{O}_{4}$. ${ }^{\mathrm{c}}$ In $0.5 \mathrm{M} \mathrm{K}_{2} \mathrm{SO}_{4}$.

From these results, it can be concluded that the resonant frequency measurement technique for determining pseudocapacitances can be used to determine heterogeneous reaction rate constants up to $0.01 \mathrm{~m} \mathrm{~s}^{-1}$. At the same time, it offers the possibility of establishing differential double-layer capacitance values in the presence of pseudocapacitance peaks.

The authors thank Prof. Dr. W. E. van der Linden for his helpful suggestions, Miss J. M. Boerrigter for preparing the manuscript, and Mr. R. H. Arends for making the drawings. 


\section{REFERENCES}

1 P. F. Seelig and R. de Levie, Anal. Chem., 52 (1980) 1506.

2 M. Ichise, H. Yamagishi, H. Oishi and T. Kohima, J. Electroanal. Chem., 106 (1980) 35.

3 C. P. M. Bongenaar, M. Sluyters-Rehbach and J. H. Sluyters, J. Electroanal. Chem. 109 (1980) 23.

4 M. Bus, Anal. Chim. Acta, 122 (1980) 387.

5 D. Britz, Anal. Chim. Acta, 115 (1980) 327.

6 S. C. Creason and D. E. Smith, J. Electroanal. Chem., 40 (1972) 1.

7 M. Sluyters-Rehbach, Ph.D. Thesis, Utrecht, 1963.

8 D. Britz and H. H. Bauer, J. Electroanal. Chem., 16 (1968) 13.

9 M. Sluyters-Rehbach and J. H. Sluyters, Recl. Trav. Chim. Pays-Bas, 82 (1963) 535.

10 N. A. Boravaya and B. B. Damaskin, Elektrokhimiya, 8 (1972) 1529.

11 S. C. Creason and D. E. Smith, Anal. Chem., 45 (1973) 2401.

12 N. Tanaka and R. Tamamushi, Electrochim. Acta, 9 (1964) 963. 